RSC-IDF Project - Chem Women Kerala

\title{
Talk in the Webinar: \\ "Inclusion: A Cornerstone \\ of Scientific Process"
}

\section{Jithin}

Published on: Apr 10, 2021

DOI: 10.21428/32c0492e.22015216

License: Creative Commons Attribution 4.0 International License (CC-BY 4.0). 


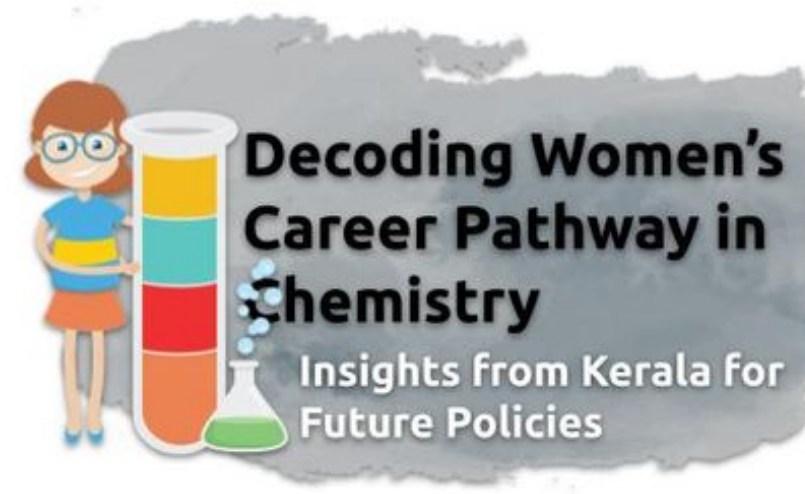

\section{"Inclusion: A Cornerstone of Scientific Progress"}

V. Jithin, P. T. Hanan, M. P. Jasil, P. Anu, K. K. Asmabi, T. C. Sreenath Women's Career Pathwey in Chemkal Sciencess a Multistage investigation in Kerala, india.

Recently, we have given a talk in the webinar "Inclusion: A Cornerstone of Scientific Process" organized by the Association of Chemistry, St. Xavier's College, Mumbai on April 4th, 2021 as part of their Chemistry Festival 'AlChemia 2021'.

The talk included some of our findings from the preliminary analyses of the data collected as part of the project.

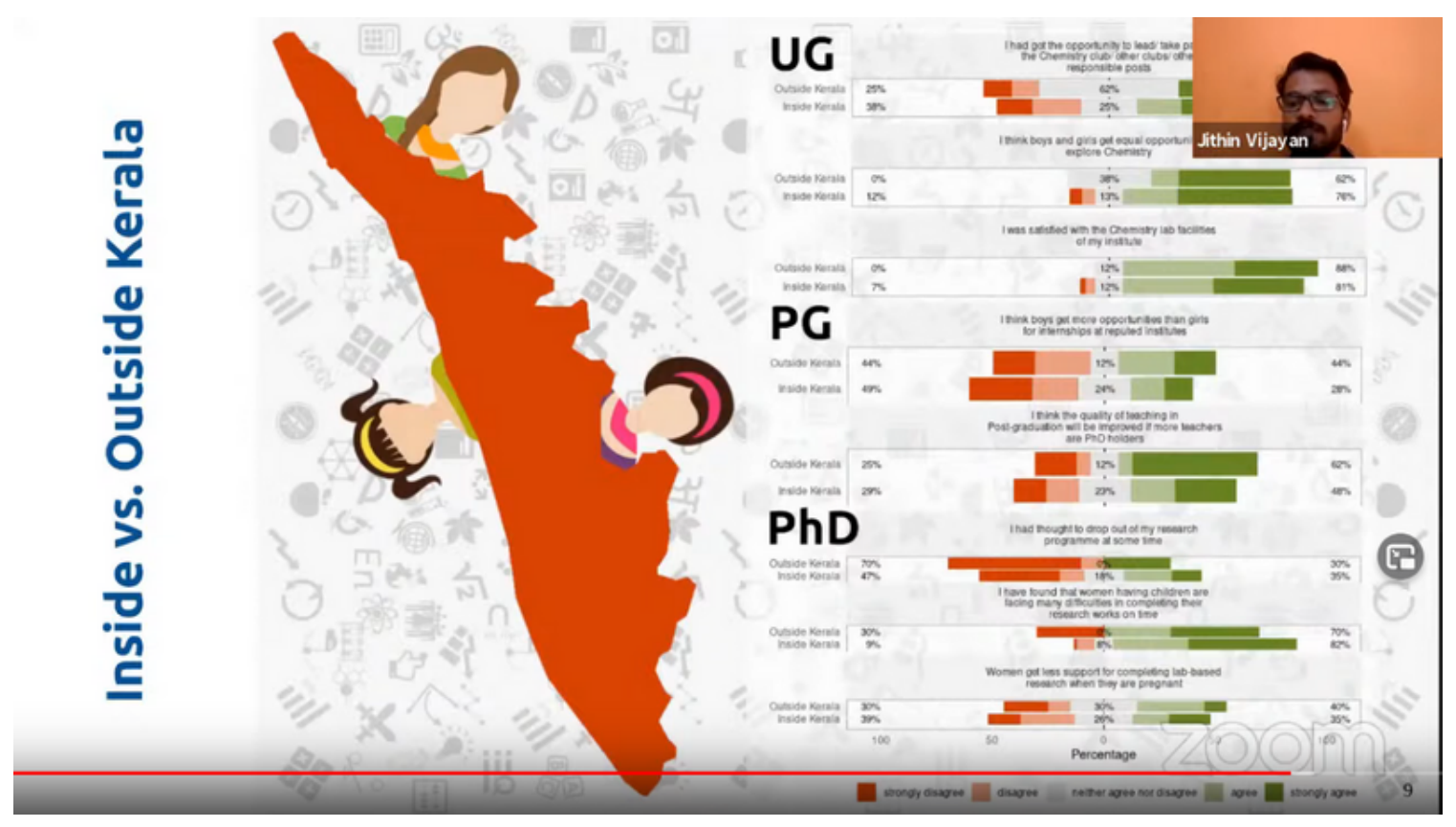


The webinar also featured two amazing and inspiring talks by Prof. Prajval Shastri (Indian Institute of Astrophysics) and Dr. Deepa Khushalani (Tata Institute of Fundamental Research).

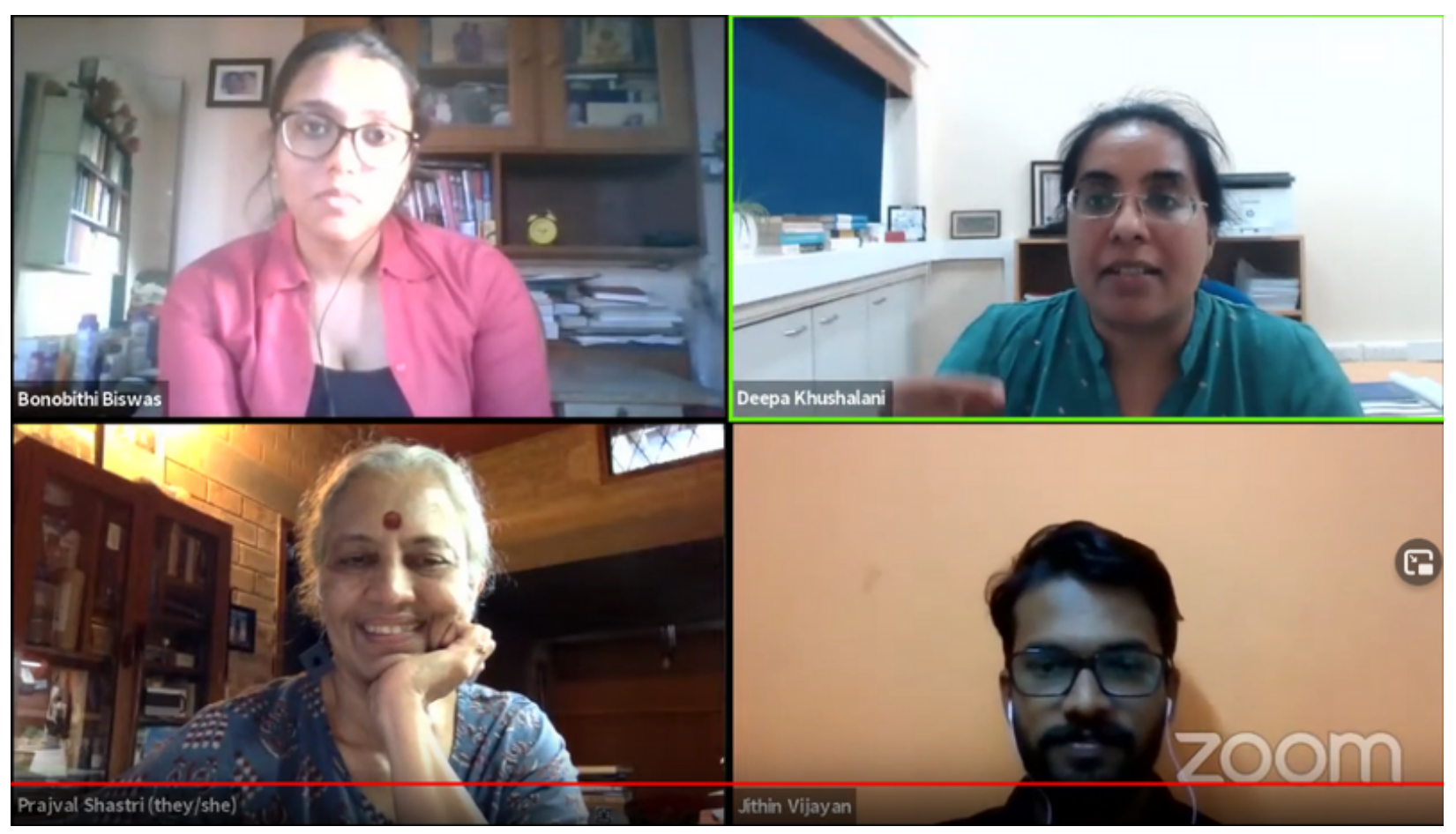

See the archived version of the webinar:

Link: https://youtu.be/oOwDYUBFywM?t=7825

Visit the web version of this article to view interactive content.

Webinar Archived Video 